\title{
Effect of sugammadex on postoperative pulmonary complications in patients with respiratory dysfunction after laparoscopic gastric or intestinal surgery: A retrospective study
}

\author{
Yiqin Ji \\ Ningbo First Hospital \\ Hui Yuan \\ Hwa Mei Hospital \\ Yijun Chen ( 13967810490@139.com ) \\ https://orcid.org/0000-0002-3209-8730

\section{Xincai Zhang} \\ Ningbo First Hospital

\section{Fan Wu} \\ Ningbo First Hospital \\ Wan Tang \\ Ningbo First Hospital \\ Zihui Lu \\ Ningbo First Hospital \\ Changshun Huang \\ Ningbo First Hospital
}

Research article

Keywords: sugammadex, postoperative pulmonary complications, respiratory dysfunction, anesthesia, laparoscopy

Posted Date: June 17th, 2020

DOl: https://doi.org/10.21203/rs.3.rs-35705/v1

License: (1) This work is licensed under a Creative Commons Attribution 4.0 International License. Read Full License 


\section{Abstract \\ Background}

Use of sugammadex is associated with fewer postoperative pulmonary complications. This study investigated the relationship between sugammadex and postoperative pulmonary complications (PPC) in specific patients with respiratory dysfunction.

\section{Methods}

The authors reviewed the electronic medical and anesthesia records of patients with respiratory dysfunction who had laparoscopic gastric or intestinal surgery at a single center between May 01, 2018, and December 31, 2019. The patients were divided into the sugammadex group and the nonsugammadex group, based on whether or not they received sugammadex. Binary logistic regression analyses were used to characterize the differences in incidence of PPC.

\section{Results}

A total of 112 patients were included, of which 46 patients (41.07\%) received sugammadex. In the logistic regression analysis, the incidences of PPC were fewer in the sugammadex group. Postoperative fever [Odds Ratio (OR) 0.330; 95\% Confidence Interval $(\mathrm{Cl}) 0.137-0.793, p=0.0213$ ], postoperative ICU admission (OR $0.204 ; 95 \% \mathrm{Cl} 0.065$ to $0.644, \mathrm{p}=0.007$ ), cough (OR $0.143 ; 95 \% \mathrm{Cl} 0.061$ to $0.333, \mathrm{p}<$ 0.001 ), pleural effusion (all) (OR: $0.280 ; 95 \% \mathrm{Cl} 0.104$ to $0.759, p=0.012$ ), pleural effusion (massive) (OR: $0.142 ; 95 \% \mathrm{Cl} 0.031$ to $0.653, \mathrm{p}=0.012$ ), and difficulty in breathing (OR: $0.111 ; 95 \% \mathrm{Cl} 0.014$ to $0.849, \mathrm{p}=$ 0.039) showed significant differences between the two groups.

\section{Conclusions}

Sugammadex-mediated reversal of neuromuscular blockade can reduce the PPC in patients with respiratory dysfunction.

\section{Background}

Respiratory function is impaired during general anesthesia [1]. Respiratory complications are associated with longer hospitalization and increased financial cost [2]. Numerous studies have explored strategies for effectively protecting respiratory function [3-4]. The use of neuromuscular blockade (NMB) drugs is related to adverse respiratory events after anesthesia. Patients with a history of pulmonary disease have increased risk of postoperative pulmonary complications (PPC) [5-6]. Neostigmine, which is a cholinesterase inhibitor reversal agent, may increase airway resistance and airway secretions. Muscarinic 
antagonists are often used to reduce side effects, but adverse pulmonary effects cannot be prevented in specific patients, such as asthmatic patients.

Sugammadex is a modified gamma-cyclodextrin, which is used for the reversal of NMB induced by aminosteroid neuromuscular blocking agents, particularly rocuronium [7-9]. It facilitated the clinical application of a high-dose muscle relaxant anesthetic technique aimed at maintaining deep NMB throughout the surgical procedure. Maintaining deep NMB improves surgical working conditions in selected laparoscopic procedures [10-11]. Sugammadex can rapidly reverse NMB, regardless of the depth of the block, and is associated with a lower risk of postoperative residual curarization after extubation [12-14]. A recent study showed that spontaneous recovery of NMB was an independent risk factor for PPC in intermediate-to-high risk patients undergoing abdominal surgery [15].

This study aimed to evaluate the relationship between sugammadex and PPC in patients with respiratory dysfunction following laparoscopic gastric or intestinal surgery.

\section{Methods}

This retrospective observational study was approved by the department of anesthesiology at Ningbo First Hospital (Approval number: 2020-R020, Approval date: February 24, 2020, Ethical committee: Ningbo First Hospital, Zhejiang-Province, China).

\section{Study population}

All laparoscopic gastric or intestinal surgery patients with respiratory dysfunction operated between May 01, 2018, and December 31, 2019, were included in this retrospective study. The requirement for informed patient consent was waived because of the retrospective non-interventional study design. The exclusion criteria were as follows: American Society of Anesthesiologists (ASA) physical status $\geq I V$, incomplete medical documentation, without pulmonary function tests or with no history of pulmonary disease before operation.

\section{Variables and outcome measurements}

The following data were extracted from the electronic medical records: age, gender, height, weight, BMI, ASA physical status, smoking status, pulmonary disease, grade of pulmonary function, functional disorder of other systems, lung function improvement exercise, length of stay in hospital, length of hospitalization after operation, hospital cost, PPC such as cough, pneumonia, pleural effusion (all), pleural effusion (little), pleural effusion (massive), difficulty in breathing, re-intubation, and complications related to ERAS. The following data were extracted from electronic anesthesia records: infusion volume, urine output, bleeding volume, operation duration, spontaneous breathing recovery time, awakening time, exhaustion time, and the rate of postoperative admission to the intensive care unit (ICU).

\section{Outcomes}


The primary outcome of this study was PPC between the two groups. The secondary outcome was the differences in postoperative ICU admission and recovery time between the two groups. All these data were collected by a team member who was blinded to the study objectives.

\section{Statistical analysis}

The sample size was based on the available data from all patients who had laparoscopic gastric or intestinal surgery between May 01,2018, and December 31,2019. The study results are presented as the number (percentage) for categorical variables or the mean \pm SD or median [interquartile range] for continuous variables, as appropriate. Normally distributed data were described as mean \pm SD and skewed data were reported as median values [interquartile range]. The association between sugammadex and PPC was studied using Pearson's $x^{2}$ test. The independent samples t-test or Mann-Whitney U test were used to compare continuous variables, and the chi-square test to compare categorical variables between the groups.

Univariate logistic regression models were performed to study the strength of the association between sugammadex and PPC. Independent variables with p-value $<0.1$ in the univariate analysis were introduced in the model. Subsequently, the effect of these variables in the number of patients in whom reversal was used or not used was evaluated [as stated, a change of $\geq 10 \%$ in the odds ratio (OR) was considered clinically relevant].

All statistical tests were two-sided and a level of 0.05 was used to indicate statistical significance. Data analysis was performed with the Statistical Package for the Social Sciences (SPSS) Advanced Statistics 21 (IBM Software Group, Chicago, IL, USA).

The variables used for matching were age, gender, height, weight, BMI, ASA physical status, smoking status, pulmonary disease, grade of pulmonary function, functional disorder of other systems, lung function improvement exercise, infusion volume, urine output, bleeding volume, surgical procedure and duration. Thereafter, linear regression analyses were performed to detect differences in length of hospital stay between the two groups. Additionally, binary logistic regression analyses were performed to characterize the differences in incidence of postoperative admission to the ICU, cough, expectoration and difficulty in expectoration, incidence of fever, overall incidence of postoperative pleural effusion, incidence of massive pleural effusion after operation, and rate of postoperative dyspnea, between the two groups after propensity score matching. A rank-sum test was performed on variables that were non-normally distributed, including infusion volume, urine output, bleeding volume, length of hospital stay, length of hospitalization after operation, hospital cost, spontaneous breathing recovery time, awakening time, and exhaustion time.

\section{Results}

A total of 977 patients had laparoscopic gastric or intestinal surgery between May 01, 2018, and December 31, 2019, at the Ningbo First Hospital. Of those patients, 865 were excluded as presented in 
Fig. 1. After exclusion, a total of 112 patients were enrolled and available for analysis (Fig. 1). Patients in the $S$ group received sugammadex $(n=46)$, while patients in the $N$ group did not receive injection of sugammadex $(n=66)$. Patient characteristics were compared between the sugammadex and nonsugammadex groups before propensity score matching in patients who underwent laparoscopic gastric cancer surgery (Table 1).

\section{Patient characteristics}

Table 1 shows the demographic and pre-operative data. There were significant differences in preoperative medications between the sugammadex and non-sugammadex groups. Table 2 shows the intraoperative data. There were significant differences in the anesthesia depth monitoring between the sugammadex and non-sugammadex groups.

Table 1

Demographic and pre-operative data

\begin{tabular}{|c|c|c|c|c|}
\hline & $\begin{array}{l}\text { Sugammadex } \\
(n=46)\end{array}$ & $\begin{array}{l}\text { Non- } \\
\text { sugammadex } \\
(n=66)\end{array}$ & $\begin{array}{l}\text { All } \\
(n=112)\end{array}$ & $\mathbf{P}$ \\
\hline Age(yr) (mean \pm SD) & $71.24 \pm 7.98$ & $70.68 \pm 8.99$ & $\begin{array}{l}70.91 \pm \\
8.55\end{array}$ & 0.057 \\
\hline Sex(males)(\%) & $38(82.61)$ & $43(65.15)$ & $81(72.32)$ & 0.054 \\
\hline ASA physical status(ASA $\geq 3)(\%)$ & $40(87.70)$ & $50(75.76)$ & $90(80.36)$ & 0.157 \\
\hline Height(cm) (mean \pm SD) & $166.35 \pm 7.00$ & $164.8 \pm 7.78$ & $\begin{array}{l}165.19 \pm \\
7.50\end{array}$ & 0.246 \\
\hline Weight(kg) (mean \pm SD) & $60.27 \pm 11.75$ & $61.01 \pm 11.02$ & $\begin{array}{l}60.71 \pm \\
11.28\end{array}$ & 0.261 \\
\hline BMI & $21.75 \pm 3.66$ & $22.51 \pm 3.47$ & $\begin{array}{l}22.20 \pm \\
3.55\end{array}$ & 0.267 \\
\hline Smoking (\%) & $25(54.35)$ & $25(37.88)$ & $50(44.64)$ & 0.122 \\
\hline $\begin{array}{l}\text { Moderate and severe pulmonary } \\
\text { dysfunction (\%) }\end{array}$ & $27(58.70)$ & $34(51.51)$ & $61(54.46)$ & 0.563 \\
\hline Pre-operative physical exercise (\%) & 19(41.30) & $40(60.60)$ & $59(52.68)$ & 0.055 \\
\hline Pre-operative medications (\%) & $19(41.30)$ & $43(65.15)$ & $62(55.36)$ & 0.020 \\
\hline Combining other disease (\%) & $18(82.61)$ & $57(86.36)$ & $95(84.82)$ & 0.603 \\
\hline \multicolumn{5}{|c|}{ The data are presented as mean \pm SD or number (percentage). } \\
\hline
\end{tabular}


Table 2

Intra-operative data

\begin{tabular}{|c|c|c|c|c|}
\hline & $\begin{array}{l}\text { Sugammadex } \\
(n=46)\end{array}$ & $\begin{array}{l}\text { Non- } \\
\text { sugammadex } \\
(n=66)\end{array}$ & $\begin{array}{l}\text { All } \\
(n=112)\end{array}$ & $\mathbf{P}$ \\
\hline Anesthesia depth monitioring (\%) & $35(76.09)$ & $36(54.55)$ & $71(63.39)$ & 0.028 \\
\hline Temperature monitioring (\%) & $28(60.87)$ & $37(56.06)$ & $57(50.890)$ & 0.249 \\
\hline $\begin{array}{l}\text { Infusion volume(ml) (interquartile } \\
\text { range) }\end{array}$ & $\begin{array}{l}1900(1500 \text { to } \\
2325)\end{array}$ & $\begin{array}{l}2000(1875 \text { to } \\
2400)\end{array}$ & $\begin{array}{l}2000(1700 \text { to } \\
2400)\end{array}$ & 0.104 \\
\hline $\begin{array}{l}\text { Transfusion volume }(\mathrm{ml}) \\
\text { (interquartile range) }\end{array}$ & $0(0$ to 0$)$ & $0(0$ to 0$)$ & $0(0$ to 0$)$ & 0.503 \\
\hline $\begin{array}{l}\text { Bleeding volume }(\mathrm{ml}) \text { (interquartile } \\
\text { range) }\end{array}$ & $0(0$ to 0$)$ & $50(50$ to 52.5$)$ & $50(22.5$ to 50$)$ & 0.104 \\
\hline $\begin{array}{l}\text { Urine output volume }(\mathrm{ml}) \\
\text { (interquartile range) }\end{array}$ & $\begin{array}{l}450(300 \text { to } \\
600)\end{array}$ & $\begin{array}{l}400(275 \text { to } \\
600)\end{array}$ & $\begin{array}{l}400(300 \text { to } \\
600)\end{array}$ & 0.227 \\
\hline Operation time $(\min )($ mean $\pm S D)$ & $218.38 \pm 67.21$ & $246.79 \pm 8.054$ & $235.27 \pm 76.10$ & 0.285 \\
\hline Anesthesia time $(\min )($ mean \pm SD $)$ & $240.60 \pm 66.13$ & $266.77 \pm 79.45$ & $256.16 \pm 75.13$ & 0.285 \\
\hline
\end{tabular}

2 Postoperative recovery

The spontaneous breathing recovery time ( 3 vs. 35 min, $p<0.001$ ), awakening time ( 4 vs. 37 min, $p<$ 0.001 ), and exhaustion time ( $6 \mathrm{vs.} 40 \mathrm{~min}, \mathrm{p}<0.001$ ) were significantly less in the sugammadex group than in the non-sugammadex group. In addition, the incidence of postoperative admission to the ICU $(8.70 \%$ vs. $31.82 \%, p=0.005)$ and fever $(19.57 \%$ vs. $42.42 \%, p=0.014)$ were significantly lower in the sugammadex group than in the non-sugammadex group (Table 3 ). 
Table 3

Postoperative data and complications

\begin{tabular}{|c|c|c|c|c|}
\hline & $\begin{array}{l}\text { Sugammadex } \\
(n=46)\end{array}$ & $\begin{array}{l}\text { Non- } \\
\text { sugammadex } \\
(n=66)\end{array}$ & $\begin{array}{l}\text { All } \\
(n=112)\end{array}$ & $\mathbf{P}$ \\
\hline $\begin{array}{l}\text { Spontaneous breathing recovery time(min) } \\
\text { (interquartile range) }\end{array}$ & $3(2$ to 10$)$ & $35(20$ to 50$)$ & $\begin{array}{l}15(2 \text { to } \\
35)\end{array}$ & $<.001$ \\
\hline Awaking time(min) (interquartile range) & $4(3$ to 12$)$ & $\begin{array}{l}37(24.5 \text { to } \\
53.5)\end{array}$ & $\begin{array}{l}17(3 \text { to } \\
420)\end{array}$ & $<.001$ \\
\hline Exhaust time(min) (interquartile range) & $6(5$ to 15$)$ & $\begin{array}{l}40(37.5 \text { to } \\
57.5)\end{array}$ & $\begin{array}{l}20(5 \text { to } \\
42)\end{array}$ & $<.001$ \\
\hline $\begin{array}{l}\text { Length of stay in hospital(days) } \\
\text { (interquartile range) }\end{array}$ & $22(17$ to 29$)$ & $23(18$ to 32$)$ & $\begin{array}{l}23(18 \text { to } \\
29)\end{array}$ & 0.273 \\
\hline $\begin{array}{l}\text { Postoperative hospital stay(days) } \\
\text { (interquartile range) }\end{array}$ & $\begin{array}{l}11(9 \text { to } \\
14.25)\end{array}$ & $13(9$ to 8$)$ & $\begin{array}{l}12(9 \text { to } \\
17)\end{array}$ & 0.143 \\
\hline $\begin{array}{l}\text { Hospital cost (Ten thousand yuan) } \\
\text { (interquartile range) }\end{array}$ & $\begin{array}{l}5.21(4.27 \text { to } \\
5.83\end{array}$ & $\begin{array}{l}5.37(4.22 \text { to } \\
6.51)\end{array}$ & $\begin{array}{l}5.30(4.26 \\
\text { to } 6.19)\end{array}$ & 0.269 \\
\hline Postoperative ICU admission (\%) & $4(8.70)$ & $21(31.82)$ & $25(22.32)$ & 0.005 \\
\hline Complication related to ERAS (\%) & $10(21.74)$ & $26(39.40)$ & $36(32.14)$ & 0.064 \\
\hline Fever (\%) & $9(19.57)$ & $28(42.42)$ & 37(33.04) & 0.014 \\
\hline \multicolumn{5}{|c|}{ The data are presented as median [interquartile range], or number (percentage). } \\
\hline & ftarouran & & & \\
\hline
\end{tabular}

\section{Postoperative pulmonary complications}

After surgery, the incidence of cough $(26.09 \%$ vs. $71.21 \%, p<0.001)$, pleural effusion (all) $(13.04 \%$ vs. $34.85 \%, p=0.015)$, pleural effusion (massive) $(4.35 \%$ vs. $24.24 \%, p=0.001)$, and difficulty in breathing $(2.17 \%$ vs. $16.67 \%, p=0.014)$ were significantly lower in the sugammadex group than in the nonsugammadex group (Table 4).

Table 5 shows the results of logistic regression analyses for postoperative complications between the two groups. Compared with the non-sugammadex group, the rate of postoperative fever (OR 0.330, $95 \%$ $\mathrm{Cl} 0.137-0.793, p=0.013$ ) decreased by $67 \%$ in the sugammadex group, and the postoperative ICU admission rate (OR $0.204,95 \% \mathrm{Cl} 0.065-0.644, \mathrm{p}=0.007$ ) decreased by $97 \%$ in the sugammadex group. In terms of PPC, the incidence of cough (OR $0.143,95 \% \mathrm{Cl} 0.061-0.033, \mathrm{p}<0.001)$, pleural effusion (all) (OR 0.280, 95\% Cl 0.104-0.759, $p=0.012$ ), pleural effusion (massive) (OR 0.142, 95\% Cl 0.031-0.653, $p$ $=0.012)$ and difficulty in breathing (OR $0.111,95 \% \mathrm{Cl} 0.014-0.653, \mathrm{p}=0.849)$ decreased by $85.7 \%, 72 \%$, $85.8 \%, 88.9 \%$, respectively, in the sugammadex group compared to the non-sugammadex group. 
Table 4

Postoperative pulmonary complications

\begin{tabular}{|lllll|}
\hline & $\begin{array}{l}\text { Sugammadex } \\
(\mathbf{n = 4 6 )}\end{array}$ & $\begin{array}{l}\text { Non-sugammadex } \\
(\mathbf{n = 6 6 )}\end{array}$ & $\begin{array}{l}\text { All } \\
(\mathbf{n = 1 1 2})\end{array}$ & $\mathbf{P}$ \\
\hline Cough (\%) & $12(26.09)$ & $47(71.21)$ & $59(52.68)$ & $<0.001$ \\
\hline Pneumonia (\%) & $12(26.09)$ & $29(43.94)$ & $41(36.61)$ & 0.073 \\
\hline Pleural effusion(all) (\%) & $6(13.04)$ & $23(34.85)$ & $29(25.89)$ & 0.015 \\
\hline pleural effusion(little) (\%) & $4(8.70)$ & $7(10.61)$ & $11(9.82)$ & 1.000 \\
\hline pleural effusion(Massive) (\%) & $2(4.35)$ & $16(24.24)$ & $18(16.07)$ & 0.004 \\
\hline Difficulty breathing (\%) & $1(2.17)$ & $11(16.67)$ & $12(10.71)$ & 0.014 \\
\hline Re-intubation (\%) & $0(0)$ & $1(1.52)$ & $1(0.89)$ & 1.000 \\
\hline Atelectasis (\%) & $0(0)$ & $1(1.52)$ & $1(0.89)$ & 1.000 \\
\hline The data are presented number (percentage). & & & \\
\hline
\end{tabular}

Table 5

Logistic regression analysis for occurrence of postoperative complications

\begin{tabular}{|llll|}
\hline Variable & OR & $95 \% \mathrm{Cl}$ & P \\
\hline Sugammadex (vs non-sugammadex) & & & \\
\hline Fever (\%) & 0.330 & 0.137 to 0.793 & 0.013 \\
\hline Postoperative ICU admission & 0.204 & 0.065 to 0.644 & 0.007 \\
\hline Cough & 0.143 & 0.061 to 0.333 & $<0.001$ \\
\hline Pleural effusion(all) & 0.280 & 0.104 to 0.759 & 0.012 \\
\hline pleural effusion(Massive) & 0.142 & 0.031 to 0.653 & 0.012 \\
\hline Difficulty breathing & 0.111 & 0.014 to 0.849 & 0.039 \\
\hline
\end{tabular}

\section{Discussion}

This was the first study on sugammadex use in patients with respiratory dysfunction diagnosed by pulmonary function test before surgery, which had more clinical significance than patients diagnosed with existing or a previous history of pulmonary disease [16]. In this study, sugammadex was associated with superior recovery of respiratory function after anesthesia compared with neostigmine in patients with pulmonary dysfunction, including consciousness recovery time, and tracheal extubation time. In this study, we defined awakening, orientation, and cooperation as consciousness recovery, and defined the time between study drug administration and consciousness recovery as consciousness recovery time. 
This retrospective study found that sugammdex achieved a shorter consciousness recovery time than neostigmine in patients with pulmonary dysfunction, which was similar to Jones et al. study [17]. The mechanism by which sugammadex reduces consciousness recovery time remains unclear, and a potential explanation is the afferenttation (muscle spindle) theory [18-19]. This theory states that afferent signals generated in muscle stretch receptors reach arousal centers in the brain to induce arousal via afferent nerve pathways. This implies that NMB has a sedative effect by decreasing afferent input and subsequent stimulation of brain arousal centers [19-20]. Tracheal extubation time was defined as the time between study drug administration to extubation, which was much shorter in the sugammadex group, as shown in a previous study [21], including in the elderly or pediatric population [22-23], because of a different mechanism than neostigmine by directly binding and rapidly inactivating steroidal neuromuscular blockers [24].

Numerous studies have investigated the influence of NMB in respiratory outcome after anesthesia, and neostigmine was shown to have direct detrimental effects [25]. In contrast, other studies reported that after administration of NMB, sugammadex was associated with fewer postoperative adverse respiratory events [26-27]. In this study, administration of sugammadex was associated with fewer PPCs, such as postoperative cough, pleural effusion (all), massive pleural effusion and breathing failure in patients with pulmonary dysfunction before operation. However, the relationship between administration of NMB and postoperative complications remains controversial [28-30]. This study showed that sugammadex administration lowered the rate of transfer to ICU in patients with pulmonary dysfunction, which was related to a lower incidence of residual NMB, which was in agreement with the findings of Yea-Ji Lee [31]. In this study, more PPCs were observed in the neostigmine group, which may result in higher rate of ICU treatment, such as ventilator therapy and the environment of ICU, and basic pulmonary disease. These factors increased the risks of pneumonia, atelectasis and other pulmonary dysfunction in these specific patients. These findings were in agreement with the results of a retrospective study, which showed that RNMB reversal with sugammadex reduced the risk of pulmonary complications in elderly ASA 3/4 patients [32]. Sugammadex usage facilitated rapid reversal of deep NMB, and the early recovery of spontaneous breathing obviously reduced the rate of unplanned admissions and transfers to the ICU after operation, especially in these pulmonary dysfunction patients, in whom the main concern was the recovery of respiratory function. A significantly higher incidence of pulmonary complications such as cough and pneumonia was observed in the non-sugammadex group. However, there was no evidence of fewer occurrence of postoperative fever in the non-sugammadex group, which may be due to some infections related to surgery, such as incision infection, intra-abdominal infection, anastomotic fistula, etc. These infections may lead to high fever.

In this study, we monitored detailed PPCs, including cough, pneumonia, pleural effusion (all), pleural effusion (little), pleural effusion (massive), difficulty in breathing, re-intubation, and atelectasis. The incidence of postoperative cough, pleural effusion (all), massive pleural effusion and breathing failure were significantly lower in the patients with pulmonary dysfunction before operation who received sugammadex. In addition, the sugammadex group tended to have a slightly lower rate of fever and total pleural effusion. However, there was no difference in CT diagnosis of pneumonia, and a small volume of 
pleural effusion was observed. In the future, a prospective study is needed to investigate the effects of sugammadex on patients with different levels of pulmonary dysfunction before operation, which will bring deeper guiding significance to clinical work in the future.

Our study also has some limitations: Firstly, previous studies have shown that PPCs are associated with higher hospital costs. This study found that administration of sugammadex was associated with fewer respiratory system complications, which was in turn closely associated with lower rate of transfer to ICU, and length of stay in hospital after surgery. Length of stay in hospital, postoperative hospitalization, and hospital costs showed no significant differences between the groups. One reason for this finding may have been the small sample size, which is a limitation of this study. The second limitation of this study was the absence of records on the costs after surgery. In the future, we will design more complete prospective studies to compare postoperative hospitalization costs. No complication related to sugammadex was observed in the sugammadex group, while the complications related to ERAS showed no difference between the two groups, which may be due to the retrospective study design. Another important reason for these negative results could be the small sample size of specific patients.

\section{Conclusions}

In conclusion, we found sugammadex can reduce PPCs and postoperative ICU admission in patients with pulmonary dysfunction, including postoperative cough, pleural effusion (all), massive pleural effusion and breathing failure. sugammadex was associated with superior recovery of respiratory function after anesthesia.

\section{Declarations}

\section{Ethics approval and consent to participate}

This retrospective observational study was approved by the department of anesthesiology at Ningbo First Hospital (Approval number: 2020-R020, Approval date: February 24, 2020, Ethical committee: Ningbo First Hospital, Zhejiang-Province, China). The requirement for informed patient consent was waived because of the retrospective non-interventional study design.

\section{Consent for publication}

Not applicable.

\section{Availability of data and materials}

The datasets used and/or analysed during the current study are available from the corresponding author on reasonable request. 
The authors declare that they have no competing interests.

\section{Funding}

None

\section{Authors' contributions}

YJ and YC participated in the design of the experiment, YJ, XZ, FW, WT and ZL participated in the data collection, $\mathrm{YJ}$ and $\mathrm{HY}$ conducted a statistical analysis of the experimental data, $\mathrm{YJ}, \mathrm{HY}$ and $\mathrm{YC}, \mathrm{CH}$ were responsible for writing the manuscript. All authors read and approved the final manuscript.

\section{Acknowledgements}

Not applicable

\section{References}

[1] Cui Y, Cao R, Li G, Gong T, Ou Y, Huang J. The effect of lung recruitment maneuvers on post-operative pulmonary complications for patients undergoing general anesthesia: A meta-analysis. PLoS One. 2019;14:e0217405. doi: 10.1371/journal.pone. 0217405.

[2] Nafiu OO, Ramachandran SK, Ackwerh R, Tremper KK, Campbell DA Jr, Stanley JC. Factors associated with and consequences of unplanned post-operative intubation in elderly vascular and general surgery patients. Eur J Anaesthesiol. 2011;28:220-224. doi: 10.1097/EJA.0b013e328342659c.

[3] Ferrando C, Suarez-Sipmann F, Tusman G. Gracia E, Mugarra A, Arocas B et al. Individualised perioperative open-lung approach versus standard protective ventilation in abdominal surgery (iPROVE): a randomised controlled trial. Lancet Respir Med. 2018;6:193-203. doi: 10.1016/S2213-2600(18)30024-9.

[4] PROVE Network Investigators for the Clinical Trial Network of the European Society of Anaesthesiology, Hemmes SN, Gama de Abreu M, Pelosi P, Schultz MJ. High versus low positive endexpiratory pressure during general anaesthesia for open abdominal surgery (PROVHILO trial): a multicentre randomised controlled trial. Lancet. 2014;9:495-503. doi: 10.1016/S0140-6736(14)60416-5.

[5] Investigators TLV. Epidemiology, practice of ventilation and outcome for patients at increased risk of postoperative pulmonary complications: LAS VEGAS-an observational study in 29 countries. Eur J Anaesthesiol. 2017;34:492-507. doi: 10.1097/EJA.0000000000000646.

[6] Serpa Neto A, da Costa LGV, Hemmes SNT, Canet J, Hedenstierna G, Jaber S, et al. The LAS VEGAS risk score for prediction of postoperative pulmonary complications: an observational study. Eur $\mathrm{J}$ 
Anaesthesiol. 2018;35:691-701. doi: 10.1097/EJA.0000000000000845.

[7] Munro A, McKeen D, Coolen J. Maternal respiratory distress and successful reversal with sugammadex during intrauterine transfusion with fetal paralysis. Int J Obstet Anesth. 2019;39:129-131. doi: 10.1016/j.ijoa.2019.01.002.

[8] Bose S, Xu X, Eikermann M. Does reversal of neuromuscular block with sugammadex reduce readmission rate after surgery? Br J Anaesth. 2019;122:294-298. doi: 10.1016/j.bja.2018.12.015.

[9] Binczak M, Fischler M, Le Guen M. Efficacy of Sugammadex in Preventing Skin Test Reaction in a Patient With Confirmed Rocuronium Anaphylaxis: A Case Report. A A Pract. 2019;13:17-19. doi: 10.1213/XAA.0000000000000973.

[10] Bruintjes MH, van Helden EV, Braat AE, Dahan A, Scheffer GJ , van Laarhoven CJ, et al. Deep neuromuscular block to optimize surgical space conditions during laparoscopic surgery: a systematic review and meta-analysis. Br J Anaesth. 2017;118:834-842. doi: 10.1093/bja/aex116.

[11] Martini CH, Boon M, Bevers RF, Aarts LP, Dahan A. Evaluation of surgical conditions during laparoscopic surgery in patients with moderate vs deep neuromuscular block. $\mathrm{Br} \mathrm{J}$ Anaesth. 2014;112:498-505. doi: 10.1093/bja/aet377.

[12] Wu TS, Tseng WC, Lai HC, Huang YH, Wu ZF. Sugammadex and laryngospasm. J Clin Anesth. 2019;56:52. doi: 10.1016/j.jclinane.2019.01.043.

[13] Szental JA, Bramley D. Neostigmine-induced weakness after sugammadex. Anaesthesia. 2019;74:253. doi: 10.1111/anae.14553.

[14] Agrò FE, Pascarella G, Piliego C. Pharmaco-economical and clinical concerns of neuromuscular blockade nowadays: the sugammadex paradox. Minerva Anestesiol. 2019;85:447-448. doi: 10.23736/S0375-9393.18.13365-7.

[15] Garutti L , Errando CL, Mazzinari G, Bellón JM, Díaz-Cambronero O, Ferrando C, et al. Spontaneous recovery of neuromuscular blockade is an independent risk factor for postoperative pulmonary complications after abdominal surgery. A secondary analysis. Eur J Anaesthesiol. 2020; 37:203-211. doi: 10.1097/EJA.0000000000001128.

[16] Amao R, Zornow MH, Cowan RM, Cheng DC, Morte JB, Allard MW. Use of sugammadex in patients with a history of pulmonary disease. J Clin Anesth. 2012;24:289-297. doi: 10.1016/j.jclinane.2011.09.006.

[17]Jones RK, Caldwell JE, Brull SJ, Soto RG. Reversal of profound rocuronium-induced blockade with sugammadex: a randomized comparison with neostigmine. Anesthesiology. 2008;109:816-824. doi: 10.1097/ALN.0b013e31818a3fee. 
[18] Chazot T, Dumont G, Le Guen M, Hausser-Hauw C, Liu N, Fischler M. Sugammade administration results in arousal from intravenous anaesthesia: a clinical and electroencephalographic observation. $\mathrm{Br} \mathrm{J}$ Anaesth. 2011;106:914-916. doi: 10.1093/bja/aer142.

[19]Dahaba AA, Bornemann H, Hopfgartner E, Ohran M, Kocher K, Liebmann M, et al. Effect of sugammadex or neostigmine neuromuscular block reversal on bispectral

index monitoring of propofol/remifentanil anaesthesia. Br J Anaesth. 2012;108:602-606. doi: 10.1093/bja/aer495.

[20]Aho AJ, Kamata K, Yli-Hankala A, Lyytikäinen LP, Kulkas A, Jäntti V. Elevated BIS and entropy values after sugammadex or neostigmine: an electroencephalographic or electromyographic phenomenon? Acta Anaesthesiol Scand. 2012;56:465-473. doi: 10.1111/j.1399-6576.2011.02647.x.

[21] Hristovska AM, Duch P, Allingstrup M, Afshari A. The comparative efficacy and safety of sugammadex and neostigmine in reversing neuromuscular blockade in adults.A Cochrane systematic review with meta-analysis and trial sequential analysis. Anaesthesia. 2018;73:631-641. doi: 10.1111/anae.14160.

[22] Gaver RS, Brenn BR, Gartley A, Donahue BS. Retrospective analysis of the safety and efficacy of sugammadex versus neostigmine for the reversal of neuromuscular blockade in children. Anesth Analg. 2019;129;1124-1129. doi: 10.1213/ANE.0000000000004207.

[23]McDonagh DL, Benedict PE, Kovac AL, Drover DR, Brister NW, Morte JB, et al. Efficacy, safety, and pharmacokinetics of sugammadex for the reversal of rocuronium- induced neuromuscular blockade in elderly patients. Anesthesiology. 2011;114:318-29. doi: 10.1097/ALN.0b013e3182065c36.

[24] Kaye AD, Kaye RJ, Cornett EM, Urits I, Orhurhu V , Viswanath O, et al. The role of sugammadex, a novel cyclodextrin compound in modern anesthesia practice: conventional neuromuscular physiology and clinical pharmacology. Expert Rev Clin Pharmacol. 2019;12:917-919. doi:

10.1080/17512433.2019.1659134.

[25] Sasaki N, Meyer MJ, Malviya SA, Stanislaus AB, MacDonald T, Doran ME, et al. Effects of neostigmine reversal of nondepolarizing neuromuscular blocking agents on postoperative respiratory outcomes: a prospective study. Anesthesiology. 2014;121:959-968. doi:

10.1097/ALN.0000000000000440.

[26] Brull SJ, Kopman AF. Current status of neuromuscular reversal and monitoring: challenges and opportunities. Anesthesiology. 2017;126:173-90. doi: 10.1097/ALN.0000000000001409.

[27] Boon M, Martini C, Broens S, Rijnsoever EV, Zwan TVD, Aarts L, et al. Improved postoperative oxygenation after antagonism of moderate neuromuscular block with sugammadex versus neostigmine after extubation in 'blinded' conditions. Br J Anaesth. 2016;117:410-411. doi: 10.1093/bja/aew246. 
[28] Kirmeier E, Eriksson LI, Lewald H, Fagerlund MJ, Hoeft A, Hollmann M, et al. Post-anaesthesia pulmonary complications after use of muscle relaxants (POPULAR): a multi-centre, prospective observational study. Lancet Respir Med. 2019;7:129-140. doi: 10.1016/S2213-2600(18)30294-7.

[29] Plaud B, Gayat E, Nicolas P. Neuromuscular monitoring and reversal: responses to the POPULAR study. Lancet Respir Med. 2019;7:e5. doi: 10.1016/S2213-2600(18)30464-8.

[30] Fuchs-Buder T. Neuromuscular monitoring and reversal: responses to the POPULAR study. Lancet Respir Med. 2019;7:e3. doi: 10.1016/S2213-2600(18)30464-8.

[31] Lee YJ, Oh AY, Koo BW, Han JW, Park JH, Hong JP ,et al. Postoperative residual neuromuscular blockade after reversal based on a qualitative peripheral nerve stimulator response: A randomised controlled trial. Eur J Anaesthesiol. 2020;37:196- 202. doi: 10.1097/EJA.0000000000001157.

[32] Ledowski T, Falke L, Johnston F, Gillies E, Greenaway M, Mel AD, et al. Retrospective investigation of postoperative outcome after reversal of residual neuromuscular blockade: sugammadex, neostigmine or no reversal. Eur J Anaesthesiol. 2014;31:423-429. doi: 10.1097/EJA.0000000000000010.

\section{Figures}

Patients undergoing gastric or intestinal surgery between January 1,2018 and December 31,2019

$$
(\mathrm{n}=977)
$$

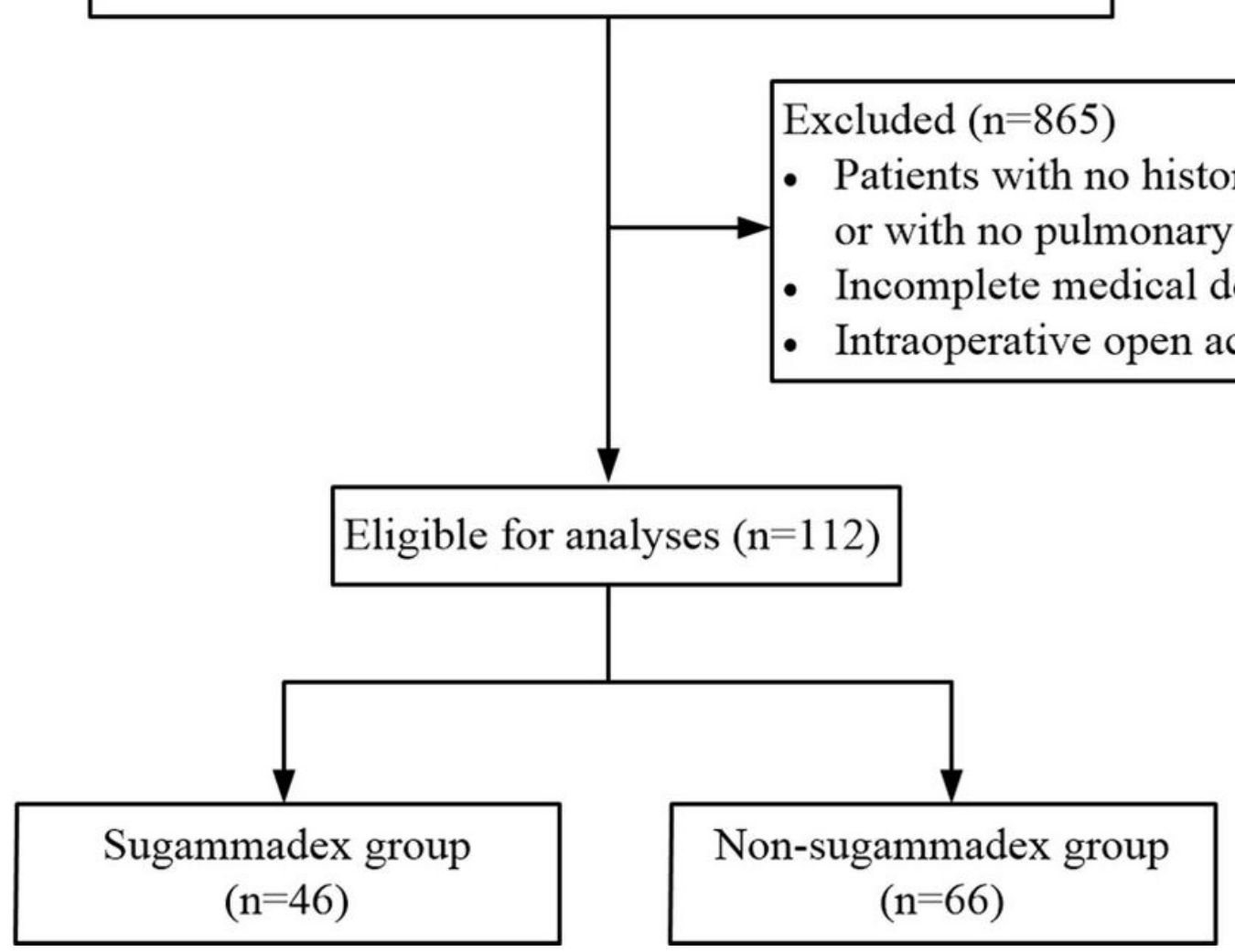




\section{Figure 1}

Flow chart depicting patient selection protocol in this study. 